\title{
The Dynamic Damage Mechanisms and Failure Modes of Coal-Rock Masses under the Action of High Order P-Waves
}

\author{
Feng Li $\left(\mathbb{D},,^{1,2}\right.$ Mingxin $\mathrm{Bi}^{2}{ }^{2}$ Jing Tian, ${ }^{2}$ and Shuhao Fang ${ }^{2}$ \\ ${ }^{1}$ Beijing Key Laboratory for Precise Mining of Intergrown Energy and Resources, China University of Mining and Technology (Beijing), \\ Beijing 100083, China \\ ${ }^{2}$ School of Resource and Safety Engineering, China University of Mining and Technology (Beijing), Beijing 100083, China
}

Correspondence should be addressed to Feng Li; lifengcumtb@126.com

Received 17 September 2017; Revised 19 February 2018; Accepted 25 March 2018; Published 8 May 2018

Academic Editor: Longjun Dong

Copyright (C) 2018 Feng Li et al. This is an open access article distributed under the Creative Commons Attribution License, which permits unrestricted use, distribution, and reproduction in any medium, provided the original work is properly cited.

\begin{abstract}
In the process of deep mining, the coal-rock masses were subjected to different types' disturbance of dynamic loading, and they propagated to the depth of coal and rock in the forms of stress waves. It has been determined that coal-rock masses mainly show shear-compression failures under static pressure. However, under dynamic loading, they had consistently demonstrated crashing or splitting failure, which showed strong dynamic mechanical characteristics. Therefore, the propagation and interaction of stress waves have great effect for the dynamical damage of coal-rock masses. The current research regarding the dynamic mechanical characteristics of coal-rock masses is still in the qualitative analysis stage, with the dynamic damage mechanism and failure modes remaining unclear. Based on the propagation characteristics of a plane strain and cylindrical wave control equations, this paper obtained a cylindrical wave propagation frequency equation and established a dynamic calculation model for the radial, axial, and shear stresses under high order P-waves. We have noticed, most surprisingly, that the amplitude directions of the radial and axial stress waves were almost opposite, with the amplitude values being basically the same when the vibration remained stable. And the vibration amplitude of shear stress wave was found to be the largest. Therefore, the coal-rock masses generally experienced tensile and shear failures under high order P-waves. The following results can be obtained: tensile failure easily occurred to the surface or axis of cylindrical coal-rock masses when there was no confining pressure, and the coal-rock masses generally experienced tensileshear failures when confining pressure was present. And we found that the vibration amplitudes and dimensionless radius $(r / R)$ were in approximately the -0.5 power relationship, and the dimensionless wave numbers $(k R)$, dimensionless frequency $(w R)$, and the wave length of stress waves propagating in cylindrical coal-rock masses were mainly within $85,(0.1 \sim 1.8) \times 10^{5}$, and $0.24 R \sim 1.08 R$ respectively.
\end{abstract}

\section{Introduction}

The buried depth is one of the main geological factors effecting coal and gas outbursts and rock burst. The increase of buried depth enhanced the potential energy for the outburst initiation due to higher crustal stress. Therefore, coal and gas outburst and rock burst accidents in China easily occur in the process of deep mining. The coal-rock masses were subjected to different types' disturbance of dynamic loading in the process of deep mining, and they propagated to the depth of coal and rock in the forms of stress waves, leading to alternating occurrence of compressive stress and tensile stress. At present, many scholars have systematically examined the static mechanical characteristics of coal-rock masses under the action of static load. Meanwhile, preliminary explorations of the dynamic mechanical characteristics under the action of dynamic loading have been made with split-Hopkinson pressure bar (SHPB) [1-6]. Coal-rock masses have been found to consistently show shear-compression failures under the action of static load [7, 8], as shown in Figure 1(a). However, the brittleness of coal-rock masses tends to increase under the action of dynamic loading, and it will always eventually display crashing or splitting failures [9], as shown in Figures 1 (b) and 1(c). And during underground chamber excavations, if the dynamic effects of transient ground stress unloading are considered, then the damage area in surrounding rock will be 


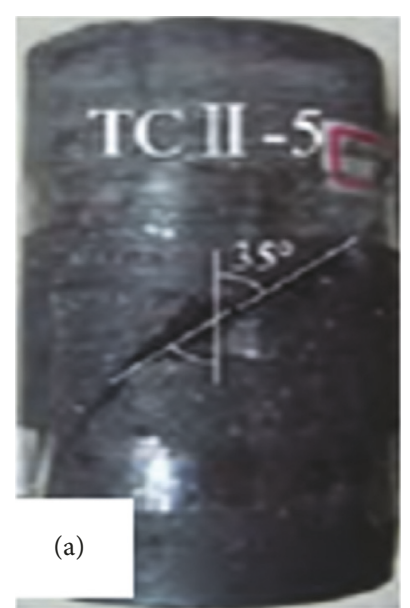

(a)

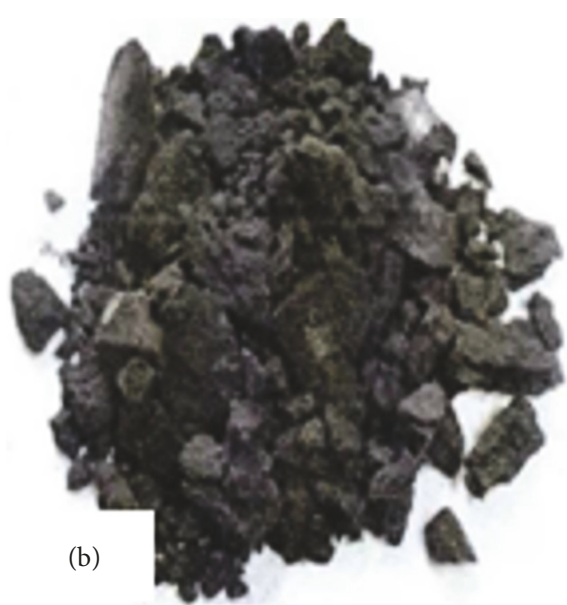

(b)

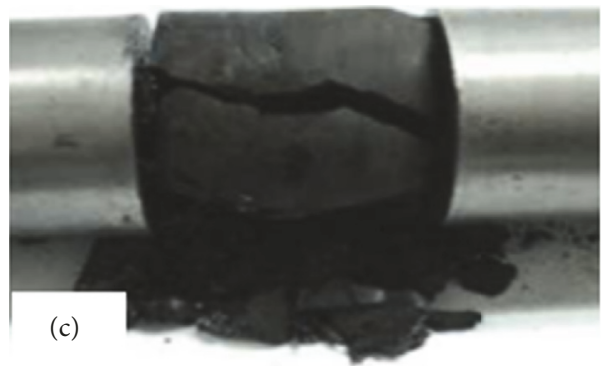

(c)

FIGURE 1: Failure mode of coal-rock masses: (a) static failure, (b) crashing failure, and (c) splitting failure.

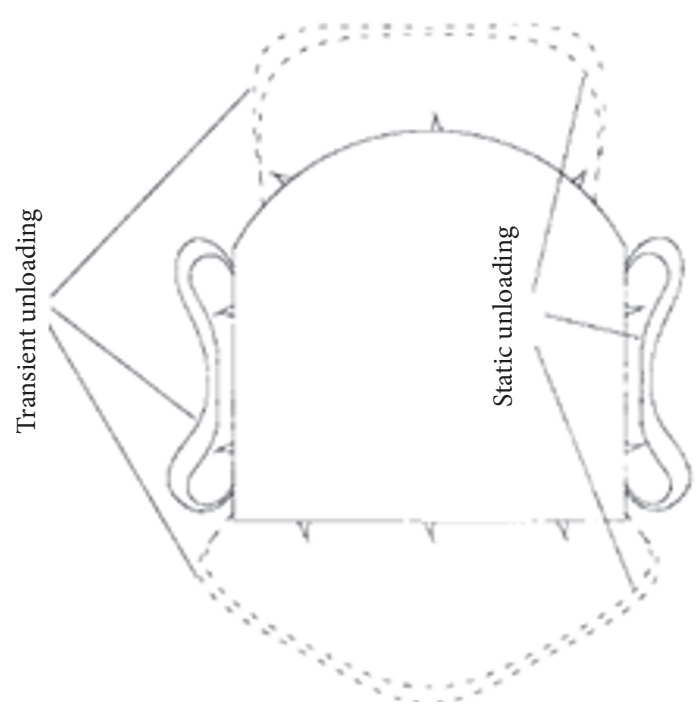

FIGURE 2: Damage distribution of the surrounding rock in a chamber under transient unloading.

obviously larger than that determined when only the quasistatic unloading effects are considered, as shown in Figure 2 [10].

According to the SHPB test results under the combined actions of dynamic and static loads, the confining pressure limited the radial deformations of coal-rock masses during initial elastic and plastic deformation stages. Therefore, the majority of damaged coal-rock masses were conical and in "V" or "X" shaped failure modes, as shown in Figure 3.

Therefore, under the action of dynamic loading, coalrock masses would show strong dynamic mechanical characteristics, and the dynamic damage and failure modes would become even more complicated [11-13]. Currently, the dynamic failure models of coal-rock masses, which have been established based on the present experimental data statistics, mainly include the K-G, KUS, and viscoelastic continuous

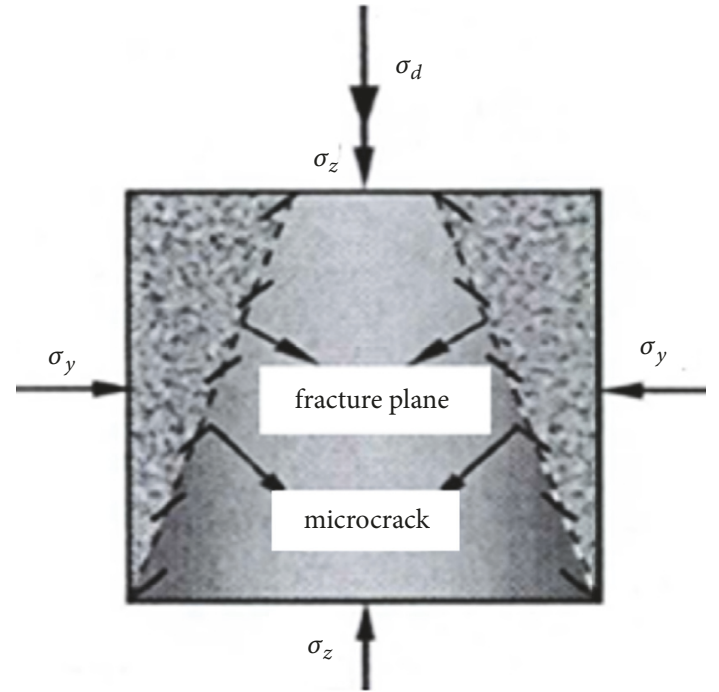

FIGURE 3: "V"-shaped failure.

damage models, along with dynamic discrete element models [14-18]. However, there still remains a lack of fundamental theory research regarding the dynamic damage mechanisms of coal-rock masses under the action of dynamic loading.

Generally speaking, the current research regarding the dynamic mechanical characteristics of coal-rock masses is still in the qualitative analysis stage, with the dynamic damage mechanisms, failure modes, and disaster-causing mechanisms remaining unclear, which seriously restricted the technology development for coal-rock dynamic disaster control. Therefore, arising from these factors and taking homogeneous cylindrical coal and rock mass for the research object, the dynamic damage mechanisms and failure modes of coal-rock masses were analyzed in the paper, and the results have important significance for the control of coal and rock dynamic disasters. 


\section{Calculation Model for the Dynamic Stress Distribution of Coal-Rock Masses}

As shown by the SHPB testing process, a bottom surface of cylindrical coal-rock mass $(z=0)$ was under the instantaneous shock of the bullet. Therefore, the cylindrical coordinates of $r, z$, and $\theta$ were selected to analyze the action of dynamic load. It was assumed that the section of coal-rock mass sample showed a plane strain after the bullet shock, and it was found to propagate in the form of plane strain wave; thus the wave control equation did not contain the variable $\theta$. With $z$ and $r$ as the axial and radial directions, respectively, the wave control equation could be expressed as follows [19]:

$$
\begin{aligned}
\frac{\partial^{2} u}{\partial t^{2}} & =a^{2} \nabla^{2} u=a^{2}\left(\frac{\partial^{2} u}{\partial r^{2}}+\frac{1}{r} \frac{\partial u}{\partial r}+\frac{\partial^{2} u}{\partial z^{2}}\right), \\
a & =\left(\frac{\lambda+2 \mu}{\rho}\right)^{1 / 2},
\end{aligned}
$$

where $u$ is the displacement; $t$ is the time; $\lambda$ and $\mu$ are the Lame coefficients; and $\rho$ is the density.

Then, we set $u=v(r, z) T(t)$ and insert it into (1) as follows:

$$
v T^{\prime \prime}=a^{2} \nabla^{2} v T
$$

After the deformation,

$$
\frac{\nabla^{2} v}{v}=\frac{T^{\prime \prime}}{a^{2} T}=-w_{0}
$$

Then,

$$
\begin{aligned}
T^{\prime \prime}+a^{2} T w_{0} & =0, \\
\nabla^{2} v+w_{0} v & =0 .
\end{aligned}
$$

With (5),

$$
T=e^{-i t a \sqrt{w_{0}}}
$$

With (6),

$$
\frac{\partial^{2} v}{\partial r^{2}}+\frac{1}{r} \frac{\partial v}{\partial r}+\frac{\partial^{2} v}{\partial z^{2}}+w_{0} v=0
$$

Then, we set $v(r, z)=R(r) Z(z)$ and insert it into (8) as follows:

$$
Z \frac{\partial^{2} R}{\partial r^{2}}+\frac{Z}{r} \frac{\partial R}{\partial r}+R \frac{\partial^{2} Z}{\partial z^{2}}+w_{0} R Z=0 .
$$

We divide both sides of (9) with $R Z$ :

$$
\frac{1}{R} \frac{\partial^{2} R}{\partial r^{2}}+\frac{1}{R r} \frac{\partial R}{\partial r}=-\frac{1}{Z} \frac{\partial^{2} Z}{\partial z^{2}}-w_{0}=-k_{0} .
$$

Then, we set $x=r \sqrt{k_{0}}$ and insert it into (10):

$$
r^{2} k_{0} \frac{\partial^{2} R}{\partial x^{2}}+r \sqrt{k_{0}} \frac{\partial R}{\partial x}+\left[\left(r \sqrt{k_{0}}\right)^{2}-0^{2}\right] R=0 .
$$

After the deformation,

$$
x^{2} \frac{\partial^{2} R}{\partial x^{2}}+x \frac{\partial R}{\partial x}+\left[x^{2}-0^{2}\right] R=0 .
$$

With (10),

$$
\frac{\partial^{2} Z}{\partial z^{2}}+\left(w_{0}-k_{0}\right) Z=0
$$

Then,

$$
Z=e^{i z \sqrt{w_{0}-k_{0}}}
$$

With (9), (12) becomes a zero-order Bessel equation, and $R$ is bounded $(R(0)<+\infty)$. Therefore, a particular solution of (12) may be as follows:

$$
\begin{aligned}
R(x) & =A \sum_{m=0}^{\infty} \frac{(-1)^{m}}{m ! \cdot \Gamma(m+1)}\left(\frac{x}{2}\right)^{2 m}=A J_{0}(x) \\
& =A J_{0}\left(r \sqrt{k_{0}}\right) .
\end{aligned}
$$

Therefore, a particular solution of the wave control equation (see (1)) can be expressed as follows:

$$
\begin{aligned}
& u(r, z, t)=A J_{0}\left(r \sqrt{k_{0}}\right) e^{i z \sqrt{w_{0}-k_{0}}} e^{-i t a \sqrt{w_{0}}} \\
& \quad=A \sum_{m=0}^{\infty} \frac{(-1)^{m}}{m ! \cdot \Gamma(m+1)}\left(\frac{r \sqrt{k_{0}}}{2}\right)^{2 m} e^{i z \sqrt{w_{0}-k_{0}}} e^{-i t a \sqrt{w_{0}}} .
\end{aligned}
$$

In order to obtain the general solution of the wave control equation and according to the Stokes-Helmholtz decomposition theorem, the displacement vector field $u$ was decomposed into irrotational and solenoidal fields. Then, the displacement vector $u$ could be expressed using scalar potential function $\varphi$ and vector potential function $\psi$ as follows:

$$
u=\nabla \varphi+\nabla \times \psi
$$

The P-wave in cylindrical coal-rock mass was an axially symmetric wave, characterized by both axial and radial displacement components. Then, in accordance with a particular solution form of the wave control equation, the forms of $\varphi$ and $\psi$ could be expressed as follows [19]:

$$
\begin{aligned}
\varphi & =A J_{0}(p r) e^{i(k z-w t)}, \\
\psi & =C J_{1}(q r) e^{i(k z-w t)}, \\
p^{2} & =\frac{w^{2}}{C_{L}^{2}}-k^{2}, \\
q^{2} & =\frac{w^{2}}{C_{T}^{2}}-k^{2},
\end{aligned}
$$

where $w$ is the wave frequency; $C_{L}$ and $C_{T}$ represent the speeds of the $\mathrm{P}$ wave and $\mathrm{S}$ wave $(\mathrm{m} / \mathrm{s})$, respectively; and $k$ is the wave number. 
The radial displacement $u_{r}$ and axial displacement $u_{z}$ of the cylindrical coal-rock mass could then be expressed as follows:

$$
\begin{aligned}
& u_{r}=\frac{\partial \varphi}{\partial r}-\frac{\partial \psi}{\partial z} \\
& u_{z}=\frac{\partial \varphi}{\partial z}+\frac{1}{r} \frac{\partial(r \psi)}{\partial r} .
\end{aligned}
$$

The zero-order and first-order Bessel functions possess the following characteristics:

$$
\begin{aligned}
\frac{d}{d x}\left[x J_{1}(x)\right] & =x J_{0}(x), \\
\frac{d}{d x}\left[J_{0}(x)\right] & =-J_{1}(x) .
\end{aligned}
$$

With (18) and (20), the radial and axial displacements could be expressed as follows:

$$
\begin{aligned}
u_{r} & =\frac{\partial \varphi}{\partial r}-\frac{\partial \psi}{\partial z}=\left[-p A J_{1}(p r)-i k C J_{1}(q r)\right] e^{i(k z-w t)} \\
u_{z} & =\frac{\partial \varphi}{\partial z}+\frac{1}{r} \frac{\partial(r \psi)}{\partial r} \\
& =\left[i k A J_{0}(p r)+q C J_{0}(q r)\right] e^{i(k z-w t)} .
\end{aligned}
$$

The calculation models for radial, axial, and shear stresses dynamic distribution are as follows:

$$
\begin{aligned}
\sigma_{r} & =\lambda\left(\frac{\partial u_{r}}{\partial r}+\frac{u_{r}}{r}+\frac{\partial u_{z}}{\partial z}\right)+2 \mu \frac{\partial u_{r}}{\partial r} \\
& =2 \mu A\left\{\frac{p}{r} J_{1}(p r)-\frac{1}{2} J_{0}(p r)\left(q^{2}-k^{2}\right)\right. \\
& \left.+i k \frac{C}{A}\left[\frac{1}{r} J_{1}(q r)-q J_{0}(q r)\right]\right\} \\
\sigma_{z} & =\lambda\left(\frac{\partial u_{r}}{\partial r}+\frac{u_{r}}{r}+\frac{\partial u_{z}}{\partial z}\right)+2 \mu \frac{\partial u_{z}}{\partial z} \\
& =2 \mu A\left[\left(p^{2}-\frac{q^{2}+k^{2}}{2}\right) J_{0}(p r)+i k q \frac{C}{A} J_{0}(q r)\right], \\
\sigma_{z r} & =\mu\left(\frac{\partial u_{r}}{\partial z}+\frac{\partial u_{z}}{\partial r}\right)=2 \mu A\left[\frac{C}{A}\left(k^{2}-q^{2}\right) J_{1}(q r)\right. \\
& \left.-2 i k p J_{1}(p r)\right] .
\end{aligned}
$$

\section{Boundary Conditions of the Dynamic Stress Calculation Model}

The radial and shear stresses on the cylindrical coal-rock masses' surfaces $(r=R)$ were zero; then, with (23) and (25),

$$
\begin{aligned}
& A\left[\frac{p}{r} J_{1}(p r)-\frac{1}{2} J_{0}(p r)\left(q^{2}-k^{2}\right)\right] \\
& \quad+C\left[\frac{i k}{r} J_{1}(q r)-i k q J_{0}(q r)\right]=0, \\
& {\left[-2 i k p J_{1}(p r)\right] A+\left[\left(k^{2}-q^{2}\right) J_{1}(q r)\right] C=0 .}
\end{aligned}
$$

In the above two equations' solutions, the determinant of the coefficient must be 0 . Then, the frequency equation of the stress waves during the propagation can be expressed as follows:

$$
\begin{aligned}
& \frac{2 p}{r}\left(q^{2}+k^{2}\right) J_{1}(p r) J_{1}(q r)-\left(q^{2}-k^{2}\right)^{2} \\
& \cdot J_{0}(p r) J_{1}(q r)-4 k^{2} p q J_{1}(p r) J_{0}(q r)=0, \\
& \frac{C}{A}=\frac{-2 i k p J_{1}(p r)}{\left(q^{2}-k^{2}\right) J_{1}(q r)} .
\end{aligned}
$$

Equation (27) is the transcendental equation of the radial wave number $k$ and frequency $w$. For every selected real wave number $k$, the infinite roots of the frequency equation could be found, and these represented the frequencies of the propagation modes in the cylindrical coal-rock mass. Then, the frequency-wave number curve, or the frequency-phase velocity curve, could be drawn.

\section{Dynamic Stress Distribution of the Cylindrical Coal-Rock Mass in a High Order P-Waves Mode}

4.1. The Frequency Equation of High Order P-Waves. If only the real root of the phase velocity $c$ between the P-waves velocity and $\mathrm{S}$-wave velocity was considered, namely, high order P-waves, then $C_{T}<c<C_{L}$. Next, the phase velocity $c(c=w / k)$ and dimensionless wave number $u(u=k R)$ formed a wave mode containing frequency $w$ and wave number $k$. We set the following:

$$
\begin{aligned}
& \alpha=\sqrt{\frac{c^{2}}{C_{T}^{2}}-1}, \\
& \beta=\sqrt{1-\frac{c^{2}}{C_{L}^{2}}}, \\
& \gamma=\frac{4 \alpha \beta}{\left(1-\alpha^{2}\right)^{2}} .
\end{aligned}
$$

The frequency equation (see (27)) of high order P-waves was changed into the following:

$$
\frac{I_{0}(u \beta) J_{1}(u \alpha)}{I_{1}(u \beta) J_{0}(u \alpha)}+\frac{2 \beta c^{2}}{u C_{T}^{2}\left(1-\alpha^{2}\right)^{2}} \frac{J_{1}(u \alpha)}{J_{0}(u \alpha)}-\gamma=0
$$

where $I_{0}$ and $I_{1}$ are 0 -order and 1-order first-class Bessel functions, respectively.

Then, assuming that $u$ is infinitely small, (30) can be simplified into the following [20]:

$$
u_{n}=\frac{1}{\alpha}\left(n \pi+\frac{\pi}{4}+\tan ^{-1} \eta\right)
$$




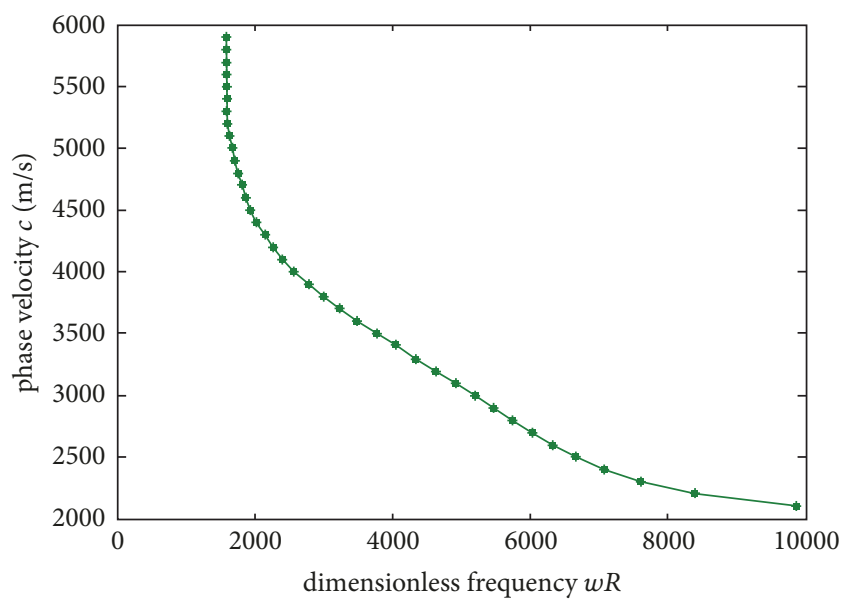

(a)

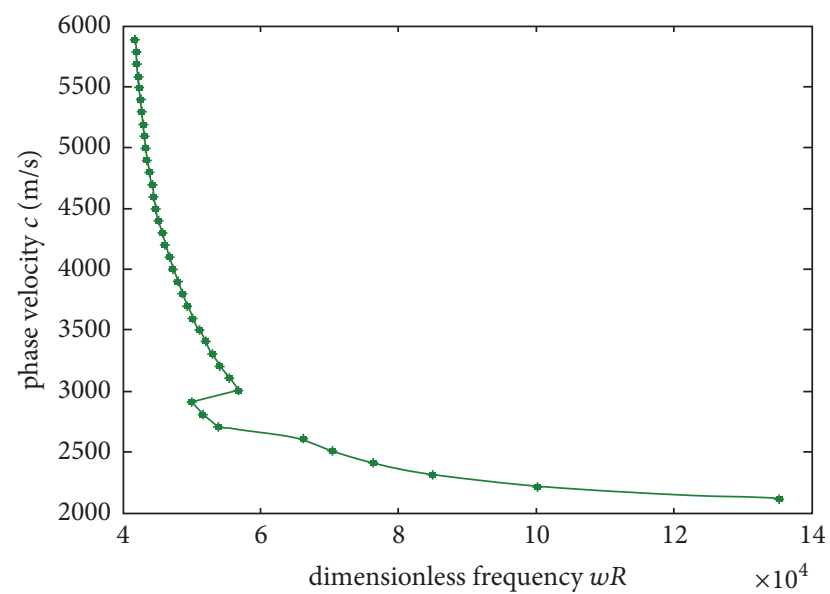

(c)

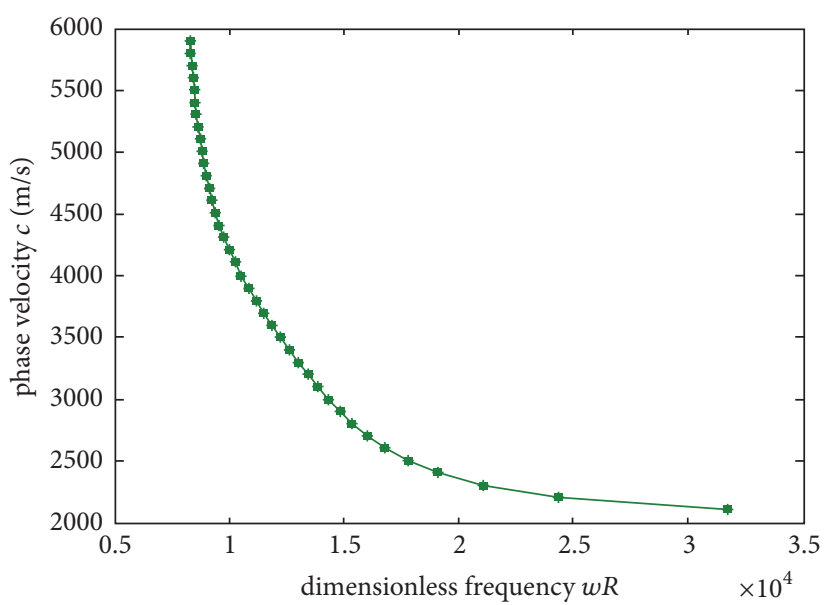

(b)

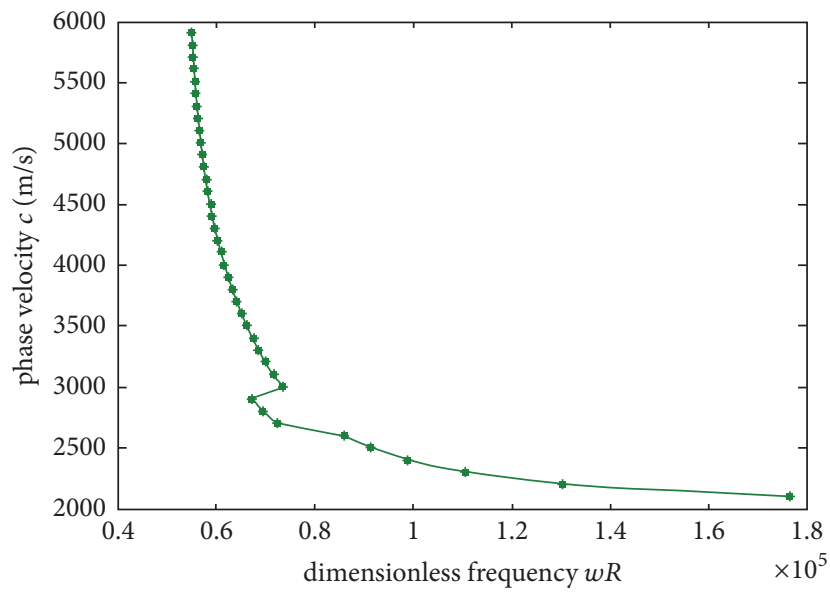

(d)

FIGURE 4: Relationships between the phase velocity and dimensionless frequency $w R$ of high order longitudinal waves: (a) $n=0$, (b) $n=1$, (c) $n=6$, and (d) $n=8$.

where

$$
\begin{aligned}
\eta & =\frac{\gamma-3 / 8 \alpha u_{n}{ }^{0}}{1+A / \alpha u_{n}{ }^{0}-\gamma / 8 \alpha u_{n}{ }^{0}}, \\
A & =\left(\frac{1}{2 \beta}+\frac{2 c^{2} \beta}{C_{T}{ }^{2}\left(\alpha^{2}-1\right)^{2}}\right) \alpha \\
u_{n}{ }^{0} & =\frac{1}{\alpha}\left(n \pi+\frac{\pi}{4}+\tan ^{-1} \gamma\right) .
\end{aligned}
$$

4.2. The Results of Frequency Equation. If the P-waves velocity of coal-rock mass was $2000 \mathrm{~m} / \mathrm{s}$ and the Poisson ratio was 0.355 , according to the simulation results of (31), the relationships between the phase velocity $c$ and dimensionless frequency $w R$ of P-waves were shown in Figure 4. The phase velocity $c$ and dimensionless frequency $w R$ of high order Pwaves showed an exponentially declining relationship. When $n$ was equal to zero, the dimensionless $w R$ was less than $1.0 \times$ $10^{4}$ and vibration frequency was very slow. When $n$ was equal to one, most of the dimensionless $w R$ were approximately
$(1 \sim 3.5) \times 10^{4}$, with the vibration frequency increasing while still remaining relatively small, which could be regarded as the startup value of dimensionless frequency $w R$. But if $n$ was equal to six or eight, the vibration frequency obviously increased, and the majority of dimensionless $w R$ centrally distributed in $(0.5 \sim 1.4) \times 10^{5}$ and $(0.6 \sim 1.8) \times 10^{5}$, respectively.

The relationships between the phase velocity $c$ and dimensionless wave number $k R$ of $\mathrm{P}$-waves were as shown in Figure 5. The phase velocity $c$ and dimensionless $k R$ of high order $\mathrm{P}$-waves also showed an exponential decline relationship. When $n$ was equal to zero, the dimensionless wave numbers $k R$ were very small and within 5 . When $n$ was equal to one, the dimensionless $k R$ increased but still remained relatively small, at less than 16 . But if $n$ was equal to six or eight, the dimensionless wave numbers $k R$ displayed obvious increases and were in 10 70 and 15 85, respectively.

4.3. The Simulation Results of Dynamic Stress Calculation Model. According to the simultaneous results based on (23) (25) and (31), under the action of high order P-waves $(n=$ $0,1,6$, and 8), dynamic distribution curves of the radial, 


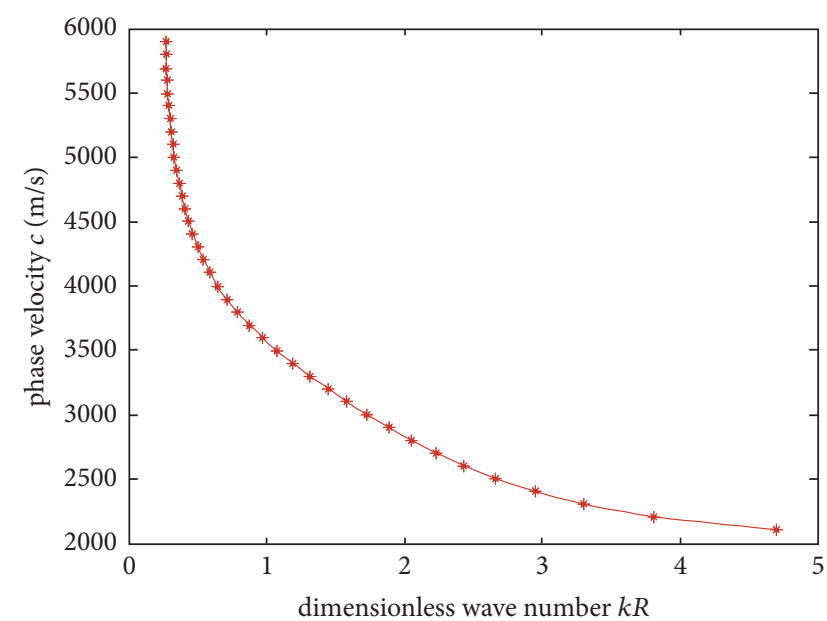

(a)

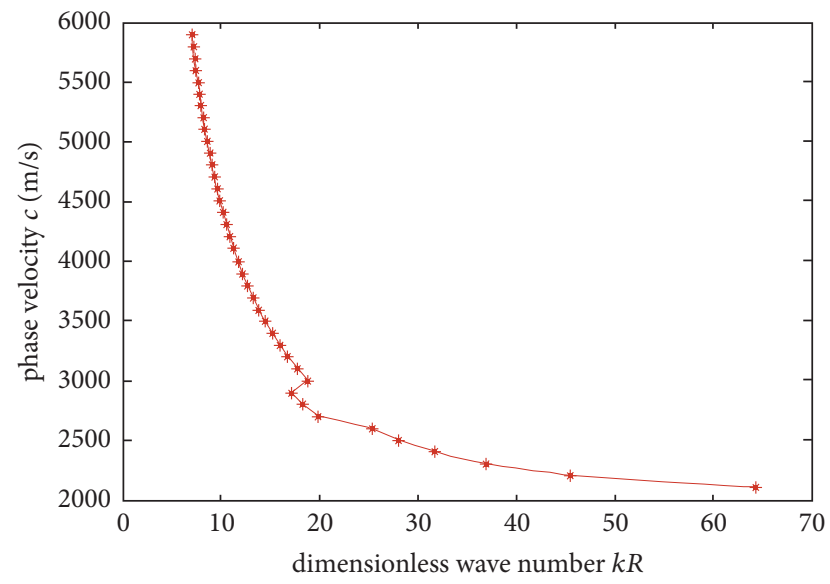

(c)

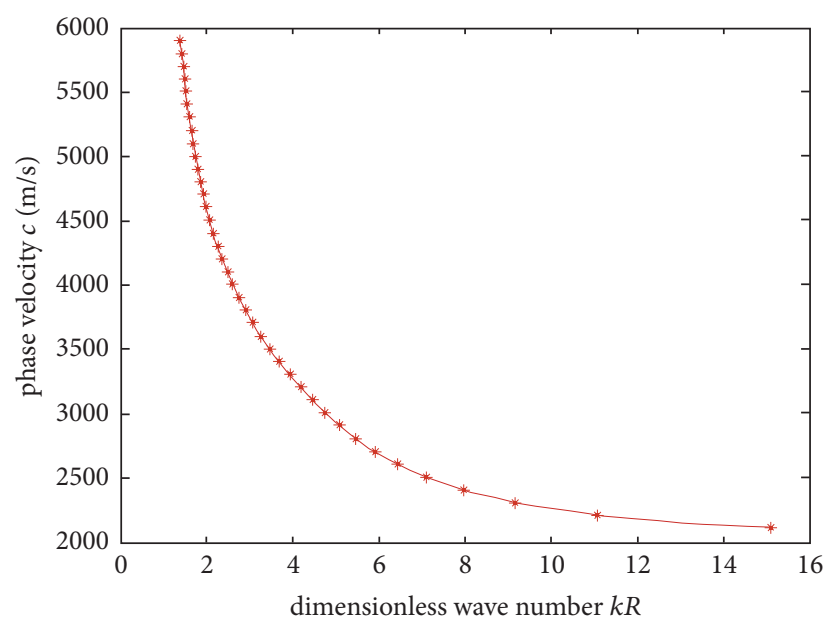

(b)

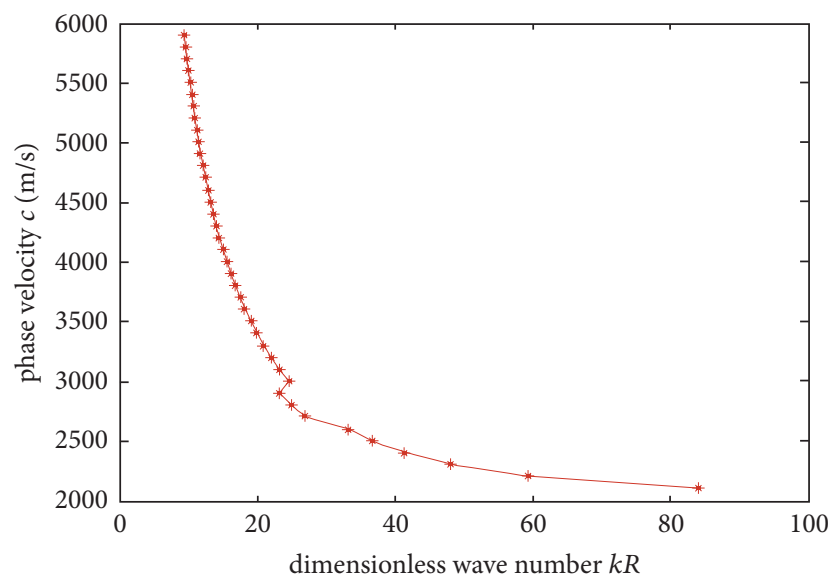

(d)

FIGURE 5: Relationships between the phase velocity and dimensionless wave number $k R$ of high order P-waves: (a) $n=0$, (b) $n=1$, (c) $n=6$, and (d) $n=8$.

axial, and shear stresses in the cylindrical section of coal-rock masses were shown in Figure 6. As shown in Figure 6, under the action of high order P-waves, the extreme amplitude of shear stress wave was determined to be the largest. The symbols of the radial and axial stress waves were almost opposite, with the amplitude values being basically the same. But their vibrations were not completely synchronous during the radial propagation of stress waves, with phase differences of approximately one half of the vibration period.

The change trends of the vibration amplitude and $r / R$ during the stress wave propagation with the extreme values of the radial, axial, and shear stress waves were then drawn as shown in Figures 7-9.

The vibration amplitudes of the radial, axial, and shear stress waves and dimensionless radius $(r / R)$ were in an approximate -0.5 power relationship as follows:

$$
\left(\sigma_{r}, \sigma_{z r}, \sigma_{z}\right)=A \cdot\left(\frac{r}{R}\right)^{-0.5},
$$

where $A$ is a constant coefficient.
Under the action of high order P-waves $(n=3,4,5$, and 7 ), the dynamic distribution curves of radial, axial, and shear stresses in the cylindrical section are shown in Figure 10.

In accordance with Figures 6-10, the following findings could be confirmed:

(1) The vibration amplitudes of the radial and axial stress waves were found to differ a great deal at the initial moment.

(2) With the increases in $r / R$, the symbols of the radial and axial stress waves were found to be almost opposite, with the amplitude values being basically the same. This indicated that, under the action of high order P-waves, the radial and axial stresses in any section of the cylindrical coal-rock mass were basically the same, and their directions were opposite. In other words, when the axial stress was a pressure stress, the radial stress was a tensile stress with the same amplitude.

(3) The vibration amplitude of the shear stress wave was determined to be the largest, at approximately 1.73 times that of the radial and axial stress waves.

(4) Under the action of high order P-waves, the wave lengths of the radial, axial, and shear stress waves were mainly in the range of $0.24 R \sim 1.08 R$. 

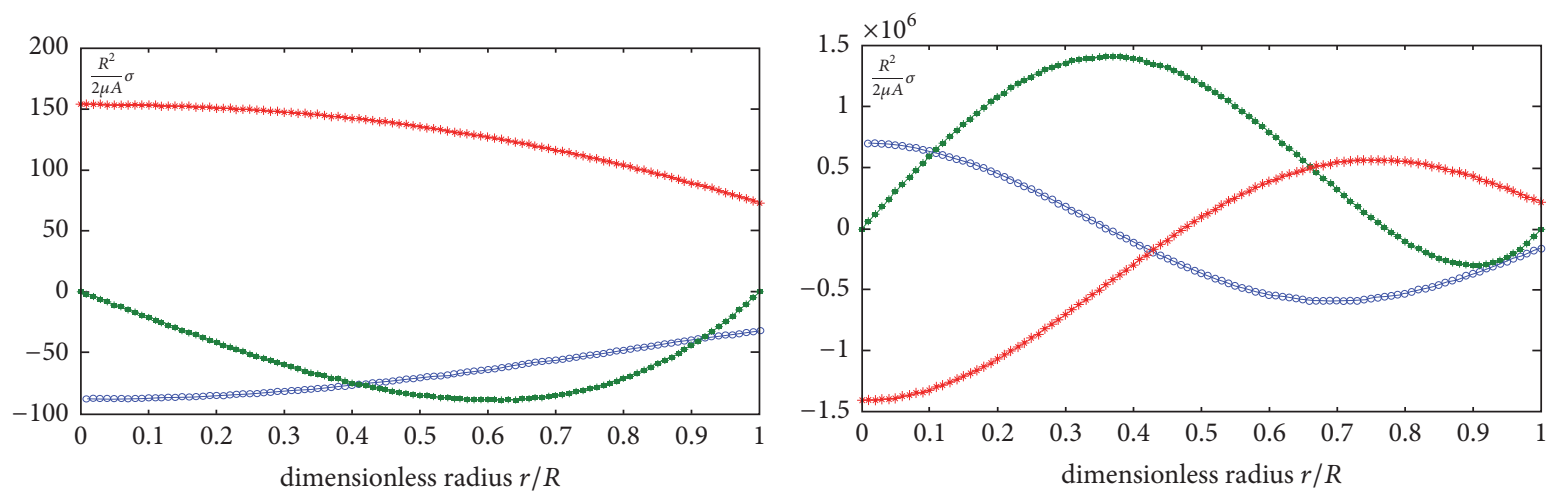

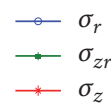

(a)

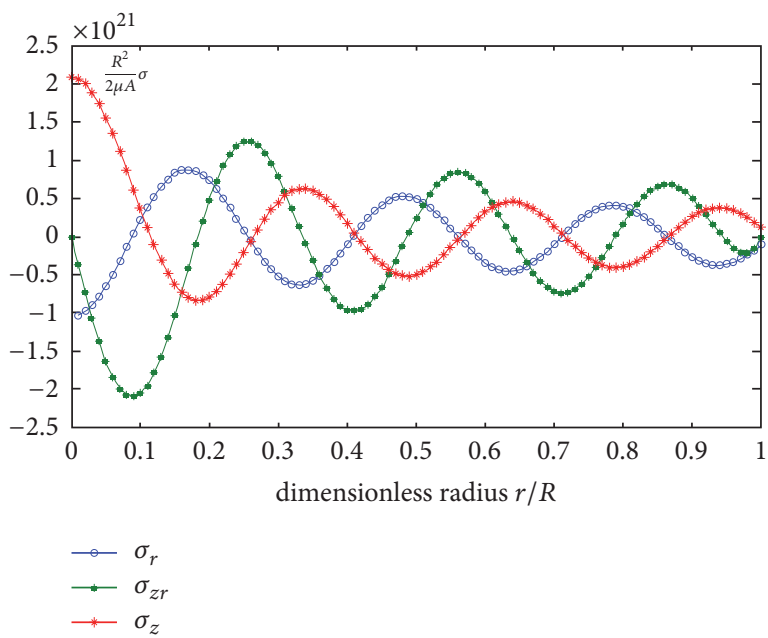

(c)

$$
\begin{array}{ll}
\longrightarrow & \sigma_{r} \\
\longrightarrow & \sigma_{z r} \\
\cdots & \sigma_{z}
\end{array}
$$

(b)

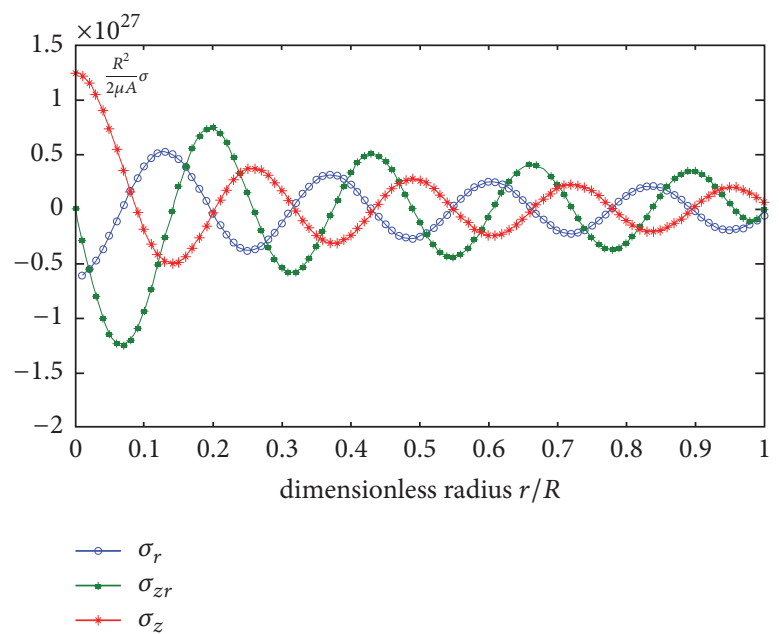

(d)

Figure 6: Dynamic distribution curves of the radial, axial, and shear stresses under the action of high order P-waves: (a) $n=0$, (b) $n=1$, (c) $n=6$, and $(\mathrm{d}) n=8$.

\section{Discussion Regarding the Dynamic Damage and Failure Modes of the Coal-Rock Masses}

Many experiments show that high amplitude acoustic emission (AE) signals would occur before the initiation of cracks in coal and rock mass under dynamic loading. In fact, each time an AE signal was generated, the coal and rock would be subjected to a transient pressure relief action propagating in the form of stress waves [21]. Most of these stress waves are composed of high order P-waves with relatively high phase velocity. A large number of AE signals were generated during the damage of coal and rock, and a lot of high order P-waves were produced at the same time.

The failure mode of marble was shown in Figure 11 under cyclic loading with the rate of loading of $1 \mathrm{kN} / \mathrm{s}$. The marble rock was brittle fracture and contained a main splitting crack with many small cracks associated with the main crack [22].

The hydraulic fracturing tests of different frequency pulsations were carried out on the cylindrical rock mass. As shown in Figure 12, the main failure form of the rock mass is the splitting failure.

By using the SHPB test system, the failure state of rock specimen under impact load with axial and confining pressure was eventually prone to cone damage, as shown in Figure 13 [3].

Therefore, we could obtain that the coal and rock mass with no confining pressure was prone to brittle splitting failure containing a main crack under high order P-waves. In addition, the initial failure positions were observed to be on the external surfaces of the ends $(z=0 ; r=R)$ or central axis $(z=0 ; r=0)$. When confining pressure was present, the radial deformations were confined, and most of coal-rock masses were eventually prone to cone damage.

The main reasons for the above dynamic failures of coalrock mass were found to be as follows: (1) the impact load action time was very short (unit: $\mu \mathrm{s}$ ), and the loading and unloading stress waves were observed to occur along the 


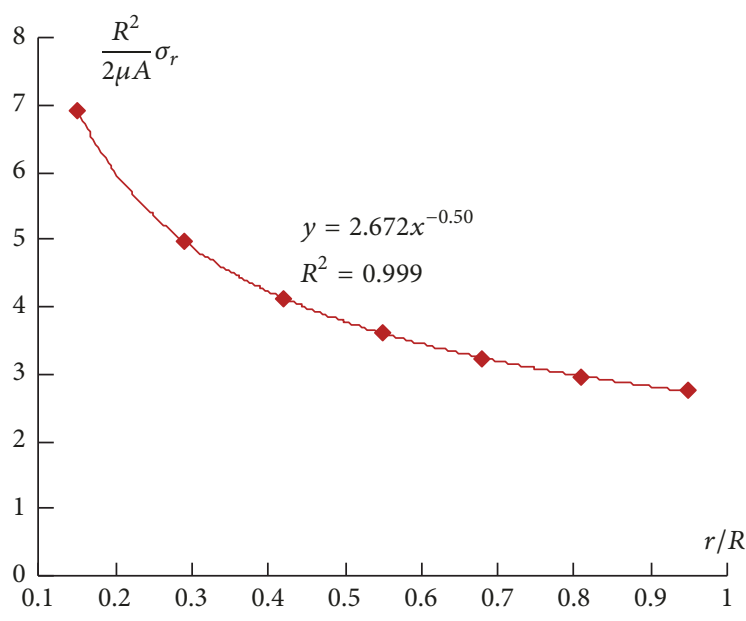

FIGURE 7: The vibration amplitude of radial stress waves.

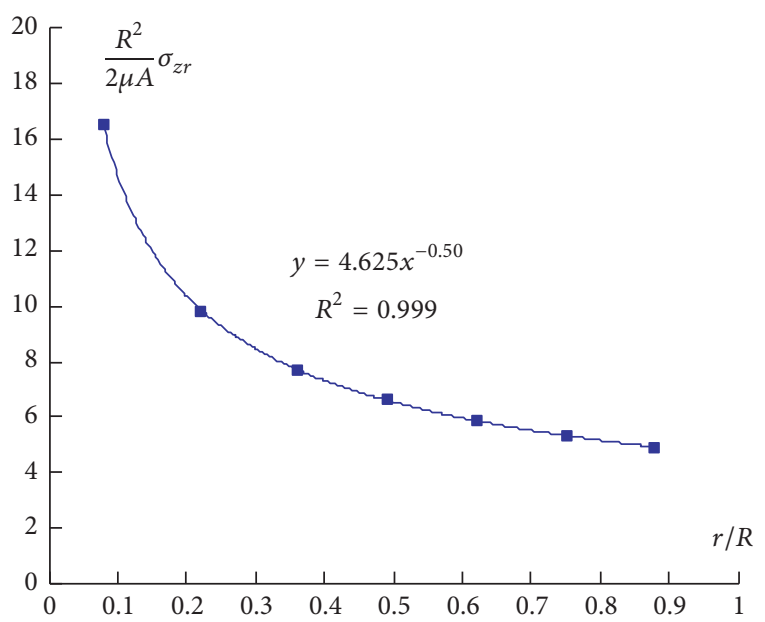

FIgURE 8: The vibration amplitude of shear stress waves.

direction of the radial sections, which formed high order P-waves. When the radial stress waves propagated to the surface $(r=R)$, they were completely reflected in the cases of no confining pressure and easily formed tensile stress waves together with the unloading stress waves. Due to the low tensile strength of coal-rock masses, tensile failure potentially formed easily on the surfaces of cylindrical coalrock masses. (2) It was observed that multibeam tensile stress waves had formed, which had arisen during the interactions of the surface reflections of cylindrical coalrock masses gathered at the axis center. In this way, largeamplitude tensile stress waves were formed, which easily led to serious tensile failure at the axis centers of the cylindrical coal-rock masses $(r=0)$. (3) When confining pressure was present, the vibration amplitude of shear stress waves along the radial section direction was observed to be the largest, and the shear stress waves were reflected and transmitted when propagating to the cylindrical coalrock mass surfaces. Moreover, the confining pressure loading devices were mainly made of steel or alloy, with large densities and strength. The majority of the reflected stress waves

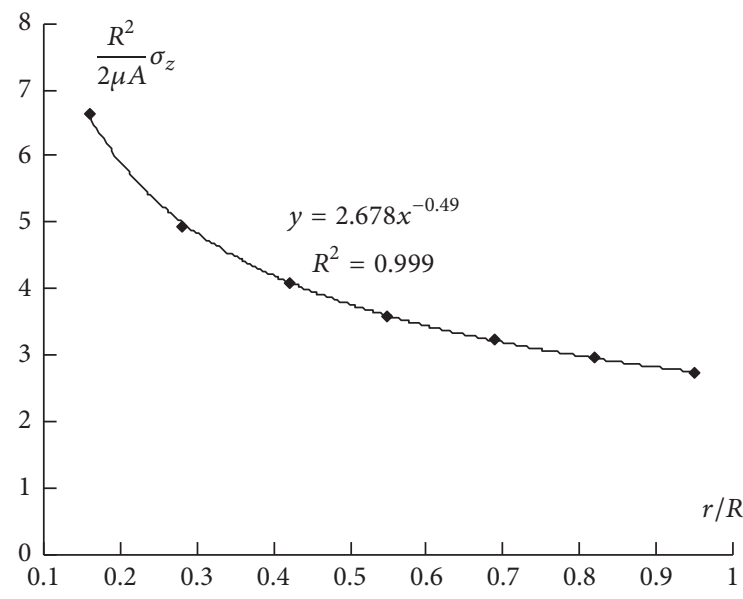

FIGURE 9: The vibration amplitude of axial stress wave.

were enhanced shear stress waves. These waves gathered at the axis centers, interacted with each other, and formed large-amplitude shear stress waves. And the shear strength of the coal-rock masses was found to be smaller than the compressive strength. Therefore, shear failures in the coalrock masses could potentially easily occur, and cone-shaped failure modes were evident.

In summary, when there was no confining pressure present, multibeam tensile stress waves were observed to form, which had arisen during the reflection of the radial stress waves on the surfaces of the cylindrical coal-rock masses under the action of high order P-waves. And they gathered at the axis centers in a reverse radial direction, resulting in interactions and the formations of largeamplitude tensile stress waves. It was found that tensile failures easily occurred on the surfaces or at the axis centers of the cylindrical coal-rock masses. However, when confining pressure was present, the vibration amplitude of the shear stress waves in the radial section direction was observed to be the largest, and the waves were reflected and transmitted on the surfaces of the cylindrical coal-rock masses. The majority of the reflected shear stress waves would be enhanced and gather at the axis centers, interacting with each other to easily form large-amplitude shear stress waves. Therefore, the coal-rock masses easily showed shear failures when confining pressure was present.

\section{Conclusions}

(1) This paper obtained a cylindrical wave propagation frequency equation and established a dynamic calculation model for the radial, axial, and shear stresses in cylindrical coal-rock masses under the action of high order P-waves, which was based on the propagation characteristics of plane strain waves, along with a cylindrical wave control equation.

(2) It was surprising that, with the increases in $r / R$, the symbols of radial and axial stress waves were almost opposite, with the amplitude values being basically the same. In other 


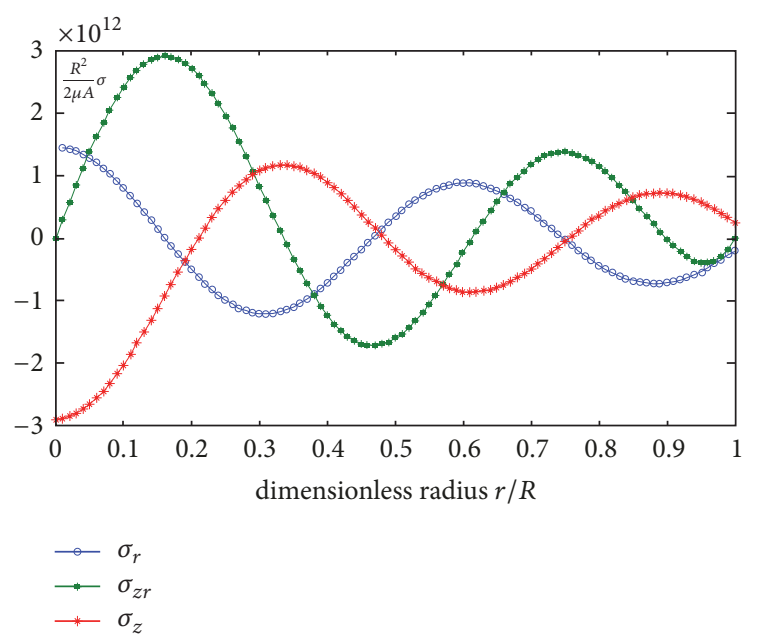

(a)

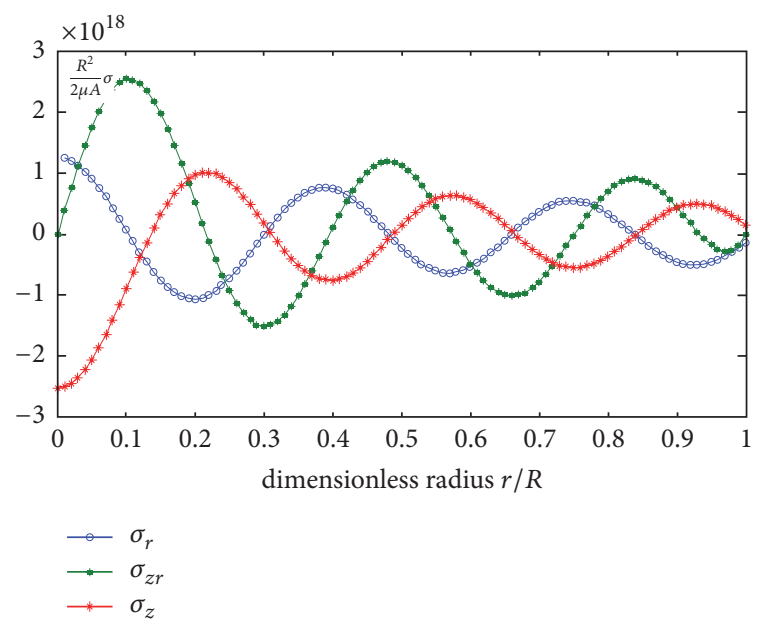

(c)

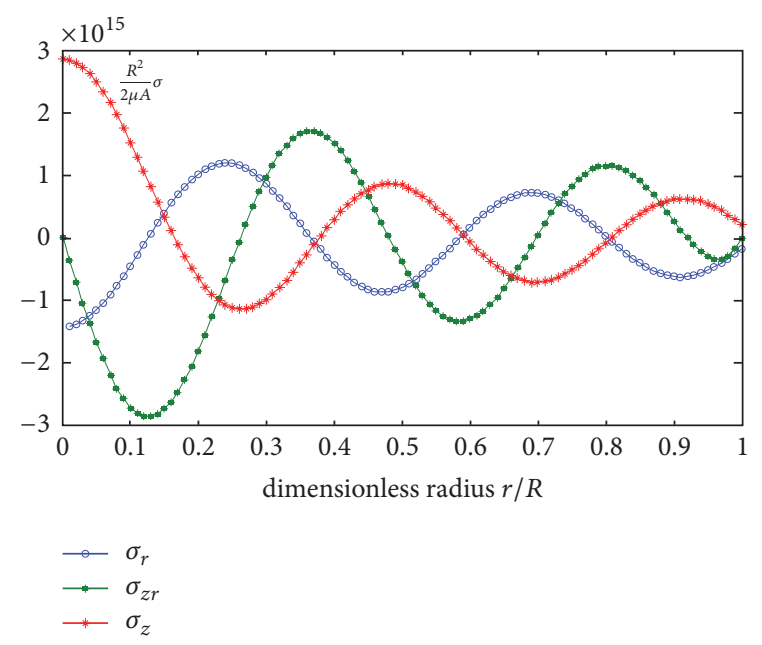

(b)

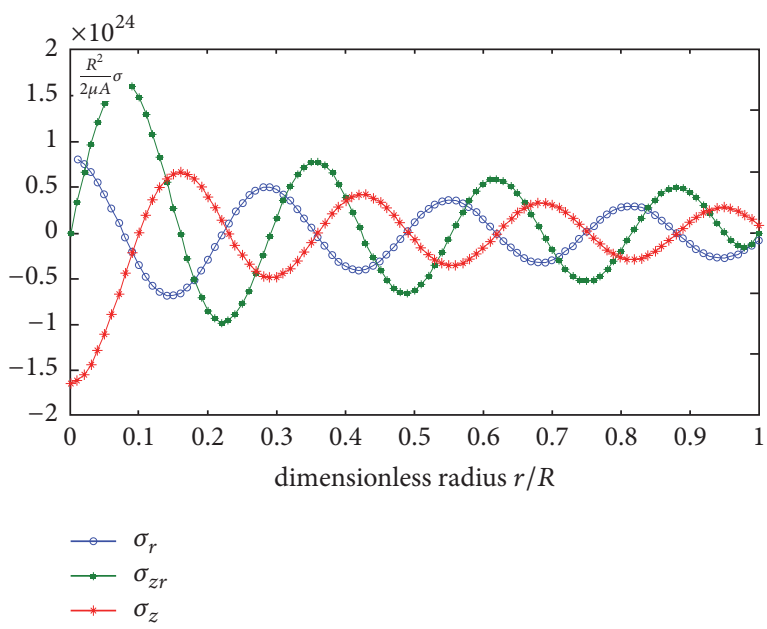

(d)

FIGURE 10: Dynamic distribution curves of the radial, axial, and shear stresses under the action of high order P-waves: (a) $n=3$, (b) $n=4$, (c) $n=5$, and (d) $n=7$.

words, when the axial stress was a pressure stress, the radial stress was a tensile stress with the same amplitude.

(3) For the cylindrical coal-rock masses under the action of high order P-waves, when there was no confining pressure, tensile failures easily occurred on the surfaces or at the axis centers. However, when there was confining pressure, it was found that shear failure easily occurred at the axis center.

(4) Under the action of high order P-waves, the dimensionless wave numbers $k R$ were within 85 , and the dimensionless frequencies $w R$ were mainly within $(0.1 \sim 1.8) \times 10^{5}$. The vibration amplitudes of shear stress waves were found to be the largest, at approximately 1.73 times those of the radial and axial stress waves. The vibration amplitudes of the stress waves and $r / R$ were all determined to be in an approximate -0.5 power relationship.

(5) Under the action of high order P-waves, the wave lengths of radial, axial, and shear stress waves propagating in the cylindrical coal-rock masses were mainly approximately within 0.24 to $1.08 R$.

\section{Symbols}

$\begin{array}{ll}u: & \text { Displacement } \\ t: & \text { Time } \\ \lambda, \mu: & \text { Lame coefficients } \\ \rho: & \text { Density } \\ w: & \text { Wave frequency } \\ C_{L}: & \text { Speed of the P-wave } \\ C_{T}: & \text { Speed of the S-wave } \\ k: & \text { Wave number } \\ u_{r}: & \text { Radial displacement } \\ u_{z}: & \text { Axial displacement } \\ c: & \text { Phase velocity } \\ R: & \text { Cylindrical radius }\end{array}$

$k R: \quad$ Dimensionless wave number

$w R: \quad$ Dimensionless wave frequency

$I_{0}$ and $I_{1}: 0$-order and 1-order first-class Bessel functions. 


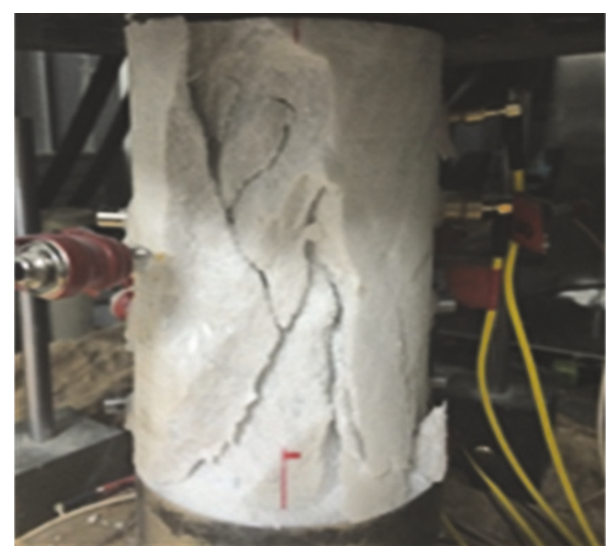

FIGURE 11: Dynamic failure mode of marble.

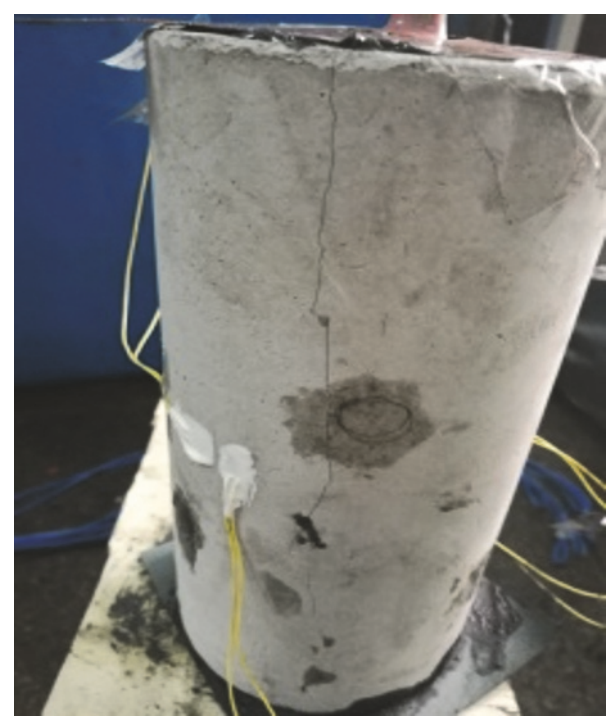

FIGURE 12: Failure mode of rock mass under pulsating hydraulic fracture.

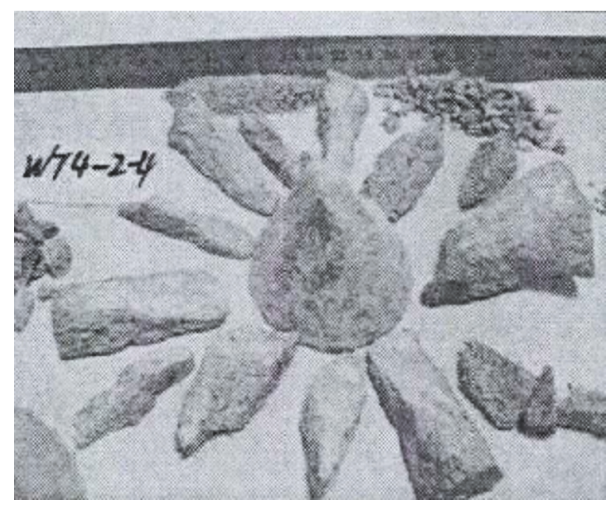

FIGURE 13: Dynamic failure mode of cylindrical rock mass with axial and confining pressure.

\section{Conflicts of Interest}

The authors declare that they have no conflicts of interest.

\section{Acknowledgments}

This study was financially supported by the National Key R\&D Program of China (2016YFC0801800) and Basic Research Free Program of Central University (2014QZ06).

\section{References}

[1] L. F. Fan, Z. J. Wu, Z. Wan, and J. W. Gao, "Experimental investigation of thermal effects on dynamic behavior of granite," Applied Thermal Engineering, vol. 125, pp. 94-103, 2017.

[2] X. B. Li, F. Q. Gong, J. K. Zhao, and T. B. Yin, "Test study of impact failure of rock subject to one dimensional coupled static and dynamic loads," Chinese Journal of Rock Mechanics and Engineering, vol. 29, no. 2, pp. 251-260, 2010.

[3] JF. Jin, Li. XB, GS. Wang, and ZQ. Yin, "Failure modes and mechanisms of sandstone under cyclic impact loadings," Journal of Central South University of Technology, vol. 43, no. 4, pp. 1453-1461, 2012.

[4] T. Szwedzicki, "A hypothesis on modes of failure of rock samples tested in uniaxial compression," Rock Mechanics and Rock Engineering, vol. 40, no. 1, pp. 97-104, 2007.

[5] J. Feng, E. Wang, R. Shen, L. Chen, X. Li, and Z. Xu, "Investigation on energy dissipation and its mechanism of coal under dynamic loads," Geomechanics and Engineering, vol. 11, no. 5, pp. 657-670, 2016.

[6] J. He, L. M. Dou, W. Cai, Z. L. Li, and Y. L. Ding, "In situ test study of characteristics of coal mining dynamic load," Shock and Vibration, vol. 2015, Article ID 121053, 8 pages, 2015.

[7] Q. S. Liu, K. D. Liu, J. B. Zhu, and X. L. Lu, "Study of mechanical properties of raw coal under high stress with triaxial compression," Chinese Journal of Rock Mechanics and Engineering, vol. 33, no. 1, pp. 24-33, 2014 (Chinese).

[8] J. S. Yoon, A. Zang, and O. Stephansson, "Simulating fracture and friction of Aue granite under confined asymmetric compressive test using clumped particle model," International Journal of Rock Mechanics and Mining Sciences, vol. 49, pp. 6883, 2012.

[9] P. F. Lv, Research on coal body permeability increase and crack generation mechanism under cumulative blasting, China University of Mining and Technology, Beijing, China, 2014.

[10] QH. Zhu, Influence on damage characteristics of surrounding rock induced by in-situ stress transient unloading, Wu Han University, 2010.

[11] L. Hong, Z.-L. Zhou, T.-B. Yin, G.-Y. Liao, and Z.-Y. Ye, "Energy consumption in rock fragmentation at intermediate strain rate," Journal of Central South University of Technology, vol. 16, no. 4, pp. 677-682, 2009.

[12] FQ. Gong, Li. XB, and XL. Liu, "Preliminary experimental study of characteristics of rock subjected to $3 \mathrm{~d}$ coupled static and dynamic loads," Chinese Journal of Rock Mechanics and Engineering, vol. 30, no. 6, pp. 1179-1190, 2011.

[13] X.-H. Liu, R. Zhang, and J.-F. Liu, "Dynamic test study of coal rock under different strain rates," Meitan Xuebao/Journal of the China Coal Society, vol. 37, no. 9, pp. 1528-1534, 2012.

[14] L. F. Fan, F. Ren, and G. W. Ma, "Experimental study on viscoelastic behavior of sedimentary rock under dynamic loading," Rock Mechanics and Rock Engineering, vol. 45, no. 3, pp. 433438, 2012.

[15] Z. Ye, X. Li, X. Liu, C. Ma, and T. Yin, "Testing studies on rock failure modes of statically loads under dynamic loading," Transactions of Tianjin University, vol. 14, pp. 530-535, 2008. 
[16] H. B. Li, J. Zhao, and T. J. Li, "Micromechanical modelling of the mechanical properties of a granite under dynamic uniaxial compressive loads," International Journal of Rock Mechanics and Mining Sciences, vol. 37, no. 6, pp. 923-935, 2000.

[17] Z.-L. Wang, Y.-C. Li, and J. G. Wang, "A damage-softening statistical constitutive model considering rock residual strength," Computers \& Geosciences, vol. 33, no. 1, pp. 1-9, 2007.

[18] J.-Q. Xiao, D.-X. Ding, G. Xu, and F.-L. Jiang, "Inverted Sshaped model for nonlinear fatigue damage of rock," International Journal of Rock Mechanics and Mining Sciences, vol. 46, no. 3, pp. 643-648, 2009.

[19] G. T. Yang, Foundations of Elastoplastic Dynamics, Science Press, Beijing, China, 2008.

[20] F. Ahmad, "A simple formula for the longitudinal modes in a cylinder," The Journal of the Acoustical Society of America, vol. 115, no. 2, pp. 475-477, 2004.

[21] L. F. Fan, X. W. Yi, and G. W. Ma, "Numerical manifold method (NMM) simulation of stress wave propagation through fractured rock mass," International Journal of Applied Mechanics, vol. 5, no. 2, Article ID 1350022, pp. 238-249, 2013.

[22] Y. F. Zhao, C. Zhang, and L. Q. Liu, "Experimental research on multi-parameter rules of rock under cyclic loading," China Safety Science Journal, vol. 26, no. 5, pp. 105-111, 2016. 


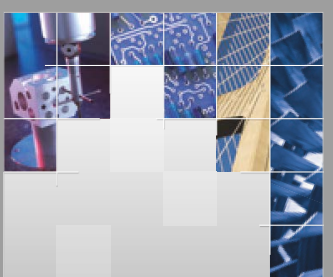

\section{Enfincering}
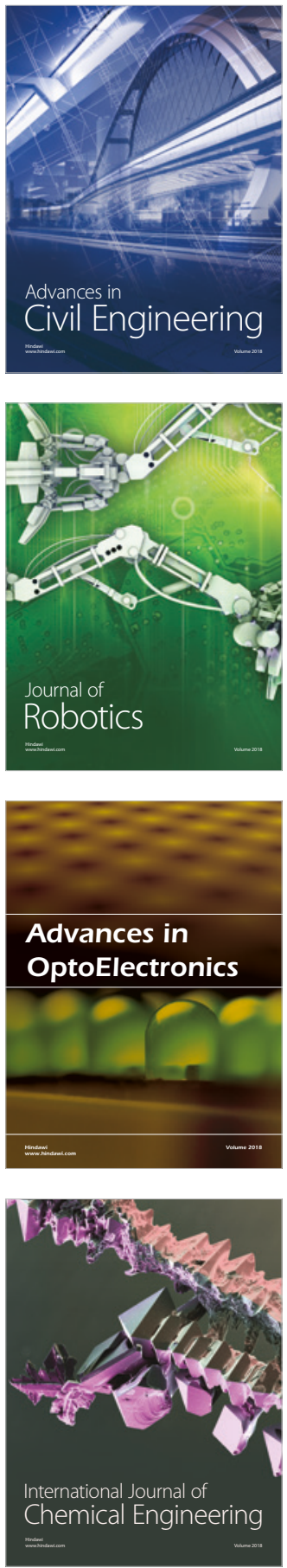

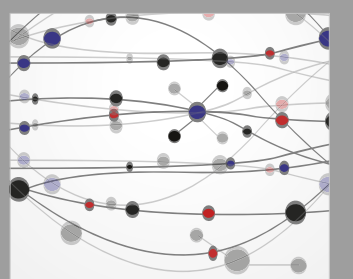

\section{Rotating \\ Machinery}

The Scientific World Journal

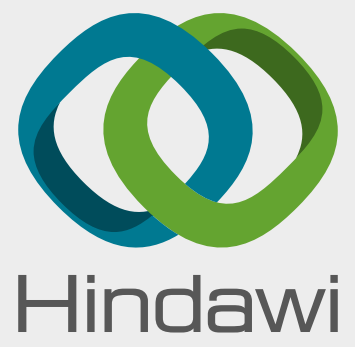

Submit your manuscripts at

www.hindawi.com
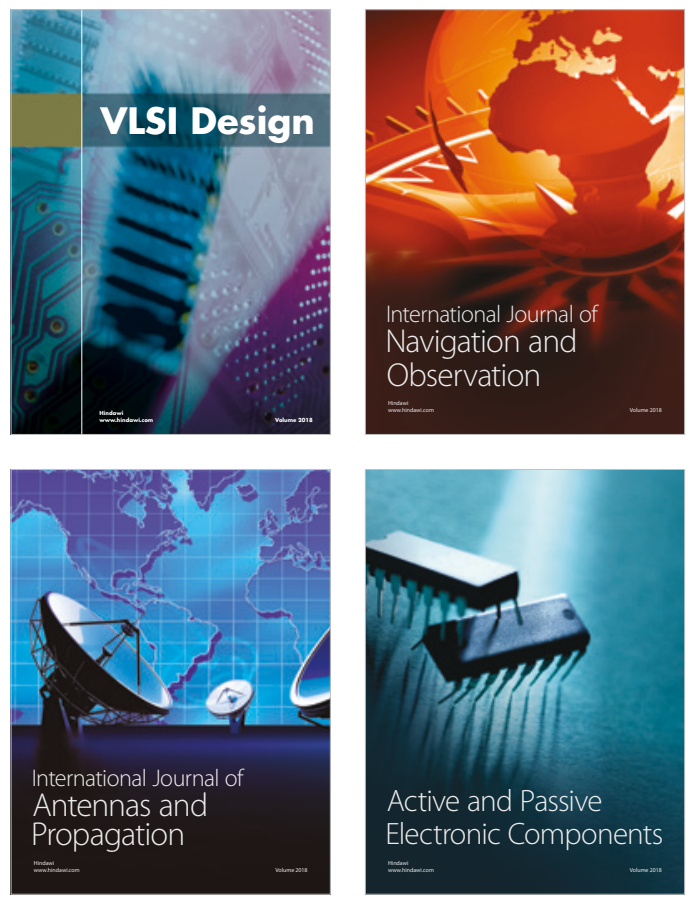
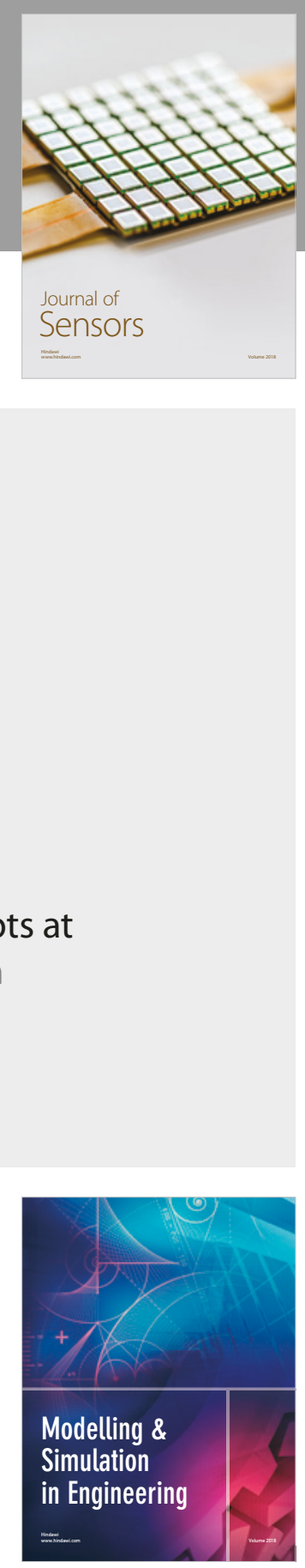

\section{Advances \\ Multimedia}
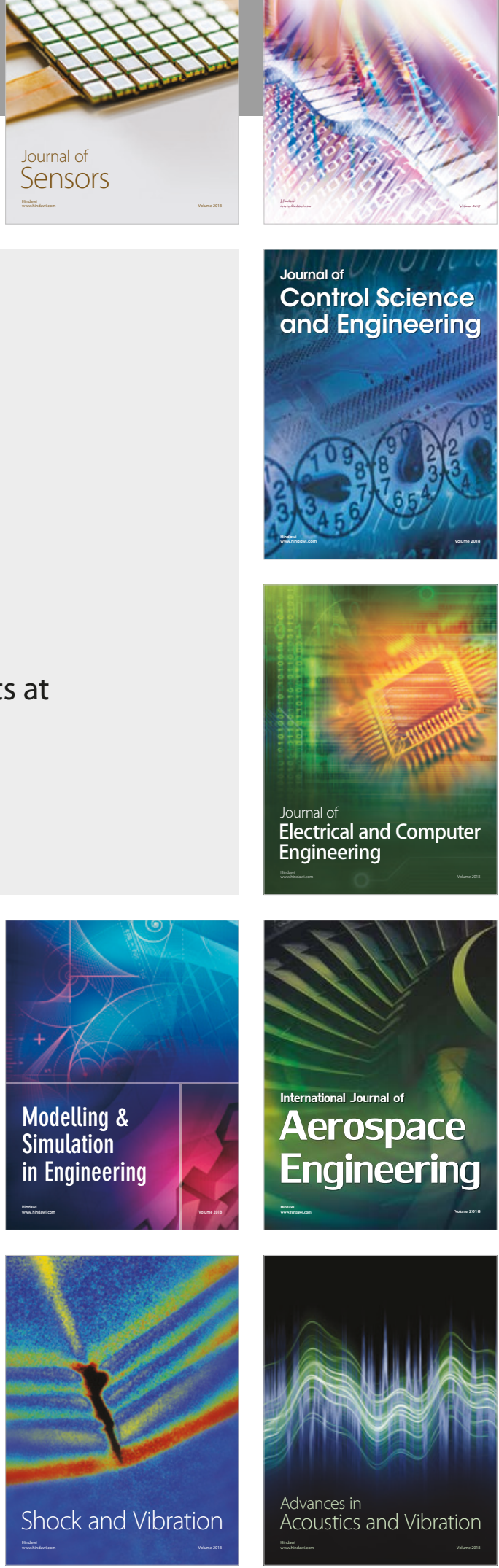